\title{
17 Essays On Modern Physics: From Sonoluminescence To Superconductivity
}

\author{
Deep Bhattacharjee ${ }^{1}$ and Deep Bhattacharjee ${ }^{2}$ \\ ${ }^{1}$ Affiliation not available \\ ${ }^{2}$ Project Director of AATWRI -R\&D Directorate of Electro-Gravitation Simulation \& \\ Propulsion Laboratory
}

August 26, 2021

\begin{abstract}
Physics is beautiful \& amazing. This paper contains 17 easy-to-read essays on modern physics over various aspects that can easily manifest a curiosity in the young minds. Essays are there without any math which entails for a easier read. They are, Complexity of Physical Law In Unification, Levitation Using Superconductivity, Cryogenics, Nuclear Energies, Speed of The Sound, To Travel In Time Is To Travel In Space, Restricted 3-Body Problem of Mechanics, Sonoluminescence, Acoustic Levitation, Evolution \& Physics, 11-Dimensional Super-Gravity, Black Hole Titbits, Frequency \& Wavelength $(\AA)$, Investigating The Possible shapes Of The Universe, Chaos \& Unpredictability, Cat's Schrodinger, Isoperimetric Inequality.
\end{abstract}

\section{Hosted file}

Essays-pdf.pdf available at https://authorea.com/users/379677/articles/535245-17-essays-onmodern-physics-from-sonoluminescence-to-superconductivity 